\title{
Analysis and Characterization of Probability Distribution and Small-Scale Spatial Variability of Rainfall in Singapore Using a Dense Gauge Network*
}

\author{
PRADEEP V. MANDAPAKA \\ Earth Observatory of Singapore, Nanyang Technological University, Singapore \\ XIAOSHENG QIN \\ Earth Observatory of Singapore, and School of Civil and Environmental Engineering, Nanyang Technological \\ University, Singapore
}

(Manuscript received 22 March 2013, in final form 3 June 2013)

\begin{abstract}
Hourly rainfall measurements from a network of 49 rain gauges on the tropical island of Singapore are analyzed to characterize variability of rainfall for temporal and spatial scales ranging from 1 to $24 \mathrm{~h}$ and from 1 to $45 \mathrm{~km}$, respectively. First, the probability distributions of rain rates are characterized using the method of $L$ moments. The analysis showed that the Pearson type-3 (PE3) distribution best fitted the rain rates for all time scales of concern. The parameters of the PE3 distribution are found to be related to the time scale through simple power laws. Second, the spatial structure of rainfall is characterized using spatial correlations. The decay of correlations with intergauge distance is parameterized using a powered-exponential function. In general, the $e$-folding correlation distance (distance at which the correlation drops to $1 / e$ ) varied from $10 \mathrm{~km}$ at hourly scales to $33 \mathrm{~km}$ at daily scales. The study also examined diurnal, seasonal, and anisotropic patterns in the spatial correlation structure of rainfall. The rainfall patterns are smoothest in December and January and are most variable in February, April, and October. Diurnal analysis of spatial correlations showed that the rainfall patterns are smoothest in the early hours between 0100 and 0600 local time and are most variable during the afternoon between 1500 and 1900 local time. The results also showed complex anisotropic patterns in spatial correlations, with considerable dependence of rainfall orientation on spatial scale and the time of the year.
\end{abstract}

\section{Introduction}

Information about the finescale (from subhourly to daily and from meters to $25 \mathrm{~km}$ ) structure of rainfall is required for a variety of applications such as spatial interpolation of rainfall (e.g., kriging), optimal design of rain gauge networks, stochastic downscaling, and evaluation of remotely sensed rainfall estimates. Better characterization of the finescale variability of rainfall is a step toward better prediction of the hydrologic response of watersheds and urban areas. Quantifying rainfall

\footnotetext{
* Supplemental information related to this paper is available at the Journals Online website: http://dx.doi.org/10.1175/JAMC-D13-0115.s1.

Corresponding author address: Pradeep V. Mandapaka, Earth Observatory of Singapore, Nanyang Technological University, 50 Nanyang Ave., Singapore 639798.

E-mail: pradeepmv@ntu.edu.sg
}

variability at very small scales is particularly important for the "Maritime Continent," where processes such as land-sea breezes and mountain-valley winds lead to complex spatial and temporal patterns in rainfall (e.g., Qian 2008). Several studies have investigated the spatial and temporal behavior of rainfall on the Maritime Continent, but a majority of them were carried out at regional scales using either satellite rainfall estimates or regional climate model simulations (e.g., Aldrian and Susanto 2003; Mori et al. 2004; Zhou and Wang 2006; Ichikawa and Yasunari 2006; Suhaila et al. 2010; Teo et al. 2011; Varikoden et al. 2011).

Very few studies investigated the variability of rainfall on the Maritime Continent at fine spatiotemporal scales (e.g., Desa and Niemczynowicz 1996a,b; Bidin and Chappell 2003, 2006). Desa and Niemczynowicz (1996a) analyzed rainfall spatial gradients and correlations using $11 \mathrm{yr}$ of data from six gauges covering approximately $300 \mathrm{~km}^{2}$ in Kuala Lumpur, Malaysia. The rainfall isohyetal maps suggested that the annual rainfall amount 


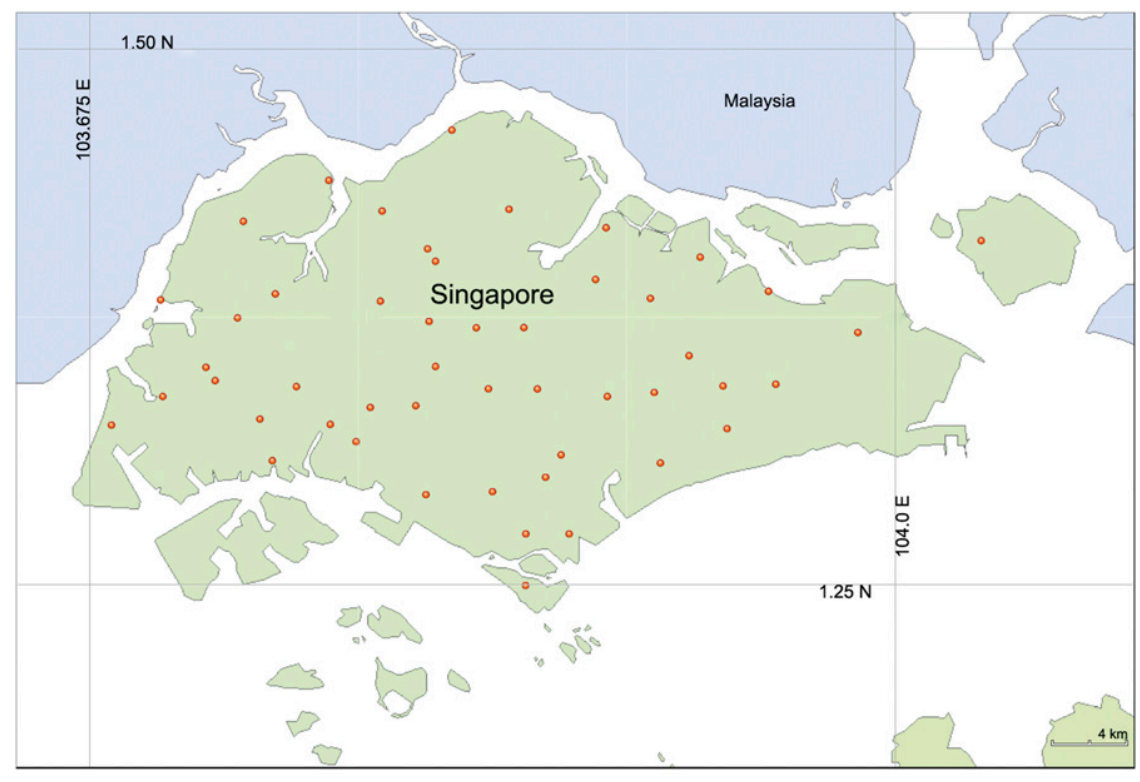

FIG. 1. Map of Singapore that shows the locations of rain gauges used in this study. There are 49 gauges distributed in an area of $\sim 710 \mathrm{~km}^{2}$.

increased from southwest to northeast. The study further reported that the spatial gradients and correlation patterns in rainfall change significantly with season of the year. For the same region, Desa and Niemczynowicz (1996b) analyzed high-resolution data of eight storms using 14 gauges distributed in an area of $23 \mathrm{~km}^{2}$ and found significant spatial variability in storm totals. Using a dense network of 46 gauges in a small humid catchment (area of $\sim 4 \mathrm{~km}^{2}$ ) in Malaysian Borneo, Bidin and Chappell (2003) studied the effects of aspect and relief on small-scale spatial structure of rainfall. The study reported "very large spatial variability or 'localisation" in annual and seasonal totals even for spatial scales as small as $1-3 \mathrm{~km}$. For the same region, Bidin and Chappell (2006) examined the spatial variation in hourly and daily rain incidence and in rain-event duration using nine gauges distributed in an area of $\sim 5 \mathrm{~km}^{2}$. The study reported shorter-duration localized rainfall events that occur particularly during midafternoon.

The aforementioned studies have improved our understanding of the small-scale rainfall variability on the Maritime Continent, in particular for peninsular Malaysia and Malaysian Borneo. The spatial and temporal scales investigated and the conclusions reached in these studies are influenced, however, by the gauge network coverage, data resolution, and length of the record. For example, Desa and Niemczynowicz (1996a) were limited by the number of gauges to model the decreasing trend of spatial correlation with intergauge distance. Furthermore, the spatial correlation analysis in the study was limited to seasonal and annual totals. Desa and Niemczynowicz (1996b), on the other hand, had better network density and data resolution but had limited length of the record. Although Bidin and Chappell (2003) used a gauge network with very high density, the study was limited to very small scales of $0.02-3.3 \mathrm{~km}$ and to seasonal and annual totals.

It can be said from the above discussion that the Maritime Continental region lacks a thorough analysis of rainfall variability at scales from hourly to daily and from tens of meters to $\sim 25 \mathrm{~km}$. The aim of this study is to bridge this gap by characterizing

1) probability density functions (PDFs) of rain rates for time scales of $1-24 \mathrm{~h}$,

2) spatial correlation structure for time scales of 1-24h and intergauge distances varying from 1 to $45 \mathrm{~km}$,

3) seasonal and diurnal behavior in finescale spatial correlations, and

4) anisotropy in finescale spatial patterns of rainfall.

We analyzed hourly data from a dense gauge network in Singapore (Fig. 1). Section 2 provides a brief description of the study area, the gauge network, and the data characteristics. Section 3 describes the analysis tools used to characterize the PDFs and spatial structure of rainfall. The results are discussed in section 4, followed by a summary and concluding remarks in section 5 .

\section{Study area and data description}

Singapore is a highly urbanized, densely populated (population of $\sim 5$ million) tropical island nation extending 

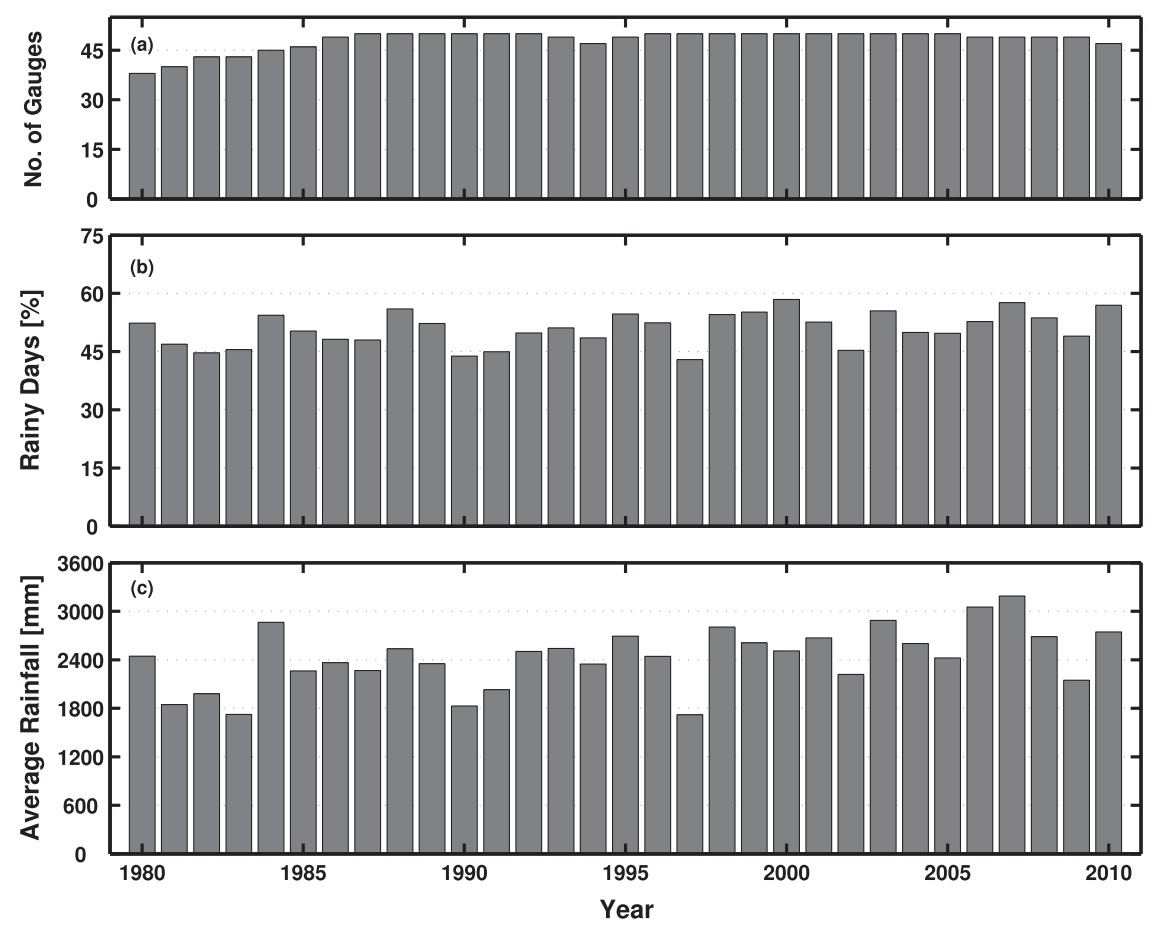

FIG. 2. (a) Number of rain gauges available, (b) average number (\%) of rainy days, and (c) average areal annual rainfall for each year of the study period (1980-2010).

from $1.16^{\circ}$ to $1.48^{\circ} \mathrm{N}$ and from $103.6^{\circ}$ to $104.09^{\circ} \mathrm{E}$, with an area of $\sim 710 \mathrm{~km}^{2}$ (Fig. 1). There is no pronounced variability in topography, with most of the island at about $15 \mathrm{~m}$ above sea level. The highest point is the Bukit Timah hill at $164 \mathrm{~m}$ above sea level near the center of the island. Because of the maritime exposure and proximity to the equator, the island is characterized by equatorial climate with high humidity, heavy rainfall, and uniformly warm temperatures throughout the year (e.g., Fong 2012). The island experiences two monsoons: the southwest monsoon from June to September and the northeast monsoon from late November to March. The prevailing winds are from a south-southeastern direction during the southwest monsoon and from a northnortheastern direction during the northeast monsoon. Typical of equatorial regions, the island has a pronounced diurnal cycle in rainfall, relative humidity, and surface winds (e.g., Fong 2012).

The data analyzed in this study were collected using a dense gauge network consisting of 49 gauges distributed in an area of $\sim 710 \mathrm{~km}^{2}$ (Fig. 1). The nearestneighbor distance between gauges varies from 0.8 to $7.9 \mathrm{~km}$, with an average value of $2.7 \mathrm{~km}$. We obtained $31 \mathrm{yr}$ (1980-2010) of hourly data from the National Environmental Agency (NEA) of Singapore. Note that the type of gauge used at some stations changed during the study period. For example, all 49 stations in 1980 were equipped with recording-type gauges with rain gauge charts attached. The precision of these gauges is $0.1 \mathrm{~mm}$. By 2010, 20 of 49 stations were equipped with tipping-bucket gauges that record the number of $0.2-\mathrm{mm}$ tips every minute. The raw data were then converted by NEA to hourly accumulations and delivered to us. The data have quality-control flags to indicate time periods with missing data. These time periods were not considered in the study.

The number of gauges available for each year of the study period is shown in Fig. 2a. Except for the initial years (1980-83), there are at least 45 gauges available for the study. The spatial coverage, gauge density, and length of the dataset are unique for this region and provide us an opportunity to perform robust analysis of rainfall structure. Note that the focus is on characterization of PDFs and spatial variability. Analysis of temporal rainfall structure is limited to studying the variation of PDFs and spatial patterns with time scale. Furthermore, the spatial structure is also analyzed according to time of day and month of the year.

The average number of rainy days (expressed as a percentage) for each year of the study period is shown in Fig. 2b. On average, it rained during $51 \%$ of days, with 1997 and 2000 recording the minimum and maximum values of $43 \%$ and $58 \%$, respectively. The average annual rainfall during the study period is $2430 \mathrm{~mm}$, with 1997 and 2007 recording minimum and maximum rainfall, respectively (Fig. 2c). The monthly variation of the 

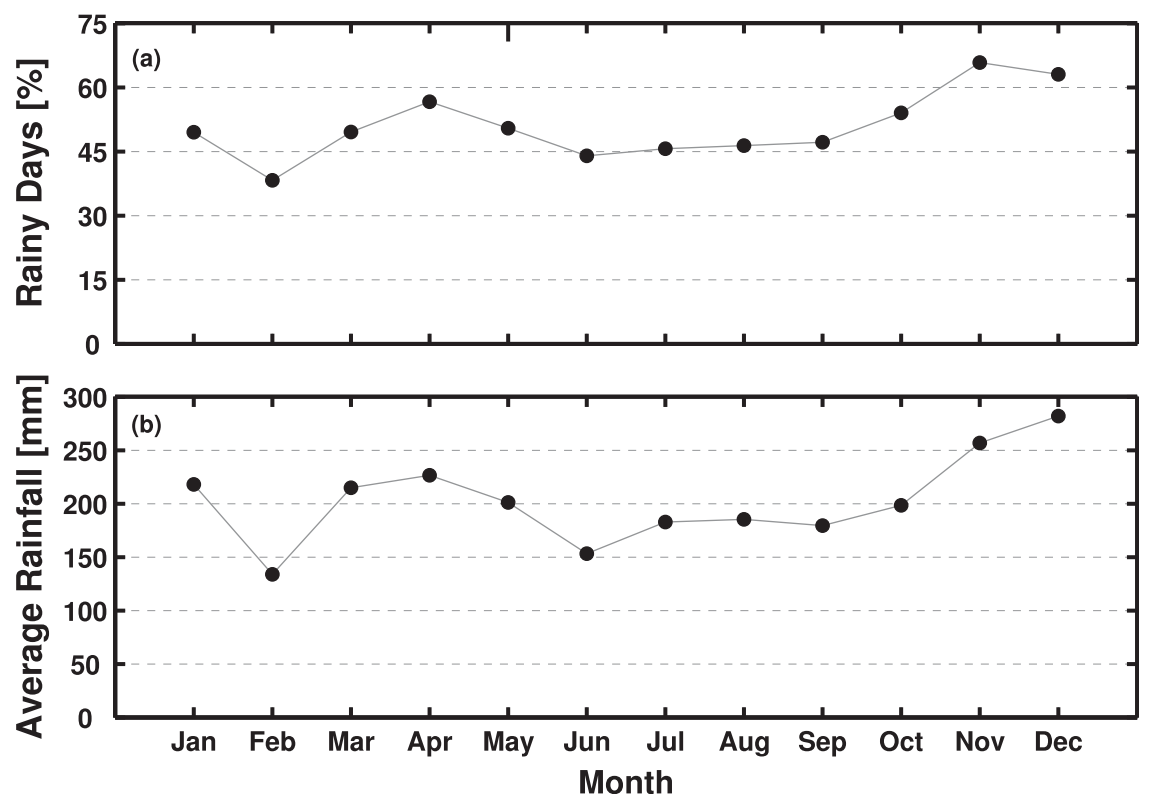

FIG. 3. (a) Average number (\%) of rainy days and (b) average areal monthly rainfall for the study period (1980-2010).

percentage of rainy days and rainfall accumulation is shown in Fig. 3. November with $66 \%$ occurrence of rainy days is the most rainy month (Fig. 3a), and December with an average rainfall of $282 \mathrm{~mm}$ is the wettest month in terms of rain amount (Fig. 3b). February recorded the lowest percentage of rainy days $(38 \%)$ and the lowest rain amount $(134 \mathrm{~mm})$.

\section{Method}

\section{a. Probability density functions: L-moment analysis}

We used the method of $L$ moments to obtain the probability density functions. The $L$ moments are linear combinations of the expectations of order statistics (Hosking 1990). The $L$-moments approach has been widely used in regional frequency analysis of rainfall and floods. The theory of $L$ moments and their advantages over conventional moments are well documented in the literature (e.g., Vogel and Fennessey 1993; Hosking and Wallis 1997).

For a given rain gauge time series, we estimated the first four $L$ moments $\left(\hat{\lambda}_{r}\right.$, where $r=1,2,3$, and 4) using the following expressions (e.g., Vogel and Fennessey 1993):

$$
\begin{aligned}
& \hat{\lambda}_{1}=\hat{\beta}_{0}, \\
& \hat{\lambda}_{2}=2 \hat{\beta}_{1}-\hat{\beta}_{0}, \\
& \hat{\lambda}_{3}=6 \hat{\beta}_{2}-6 \hat{\beta}_{1}+\hat{\beta}_{0}, \text { and } \\
& \hat{\lambda}_{4}=20 \hat{\beta}_{3}-30 \hat{\beta}_{2}+12 \hat{\beta}_{1}-\hat{\beta}_{0},
\end{aligned}
$$

where $\hat{\beta}_{r}$ is the probability weighted moment, which can be estimated from data as

$$
\hat{\beta}_{r}=\frac{1}{n}\left(\begin{array}{c}
n-1 \\
r
\end{array}\right)^{-1} \sum_{i=r+1}^{n}\left(\begin{array}{c}
i-1 \\
r
\end{array}\right) x_{i: n} .
$$

In Eq. (2), $n$ is the sample size and $x_{i: n}$ represents an ordered sample such that $x_{1: n} \leq x_{2: n} \leq x_{n: n}$. The derivations for the above expressions are available in the literature (Hosking 1990; Vogel and Fennessey 1993; Hosking and Wallis 1997). From the $L$ moments, we estimated $L$ kurtosis $\left(\tau_{3}=\hat{\lambda}_{3} / \hat{\lambda}_{2}\right)$ and $L$ skewness $\left(\tau_{4}=\hat{\lambda}_{4} / \hat{\lambda}_{2}\right)$, which are then compared with the values of theoretical distributions in the $L$-moment ratio $\left(\tau_{3}\right.$ vs $\tau_{4}$ ) diagram to identify a suitable PDF. Once a suitable PDF is identified, we estimated its parameters from $L$ moments using formulas given by Hosking and Wallis (1997). The goodness-of-fit of the PDF is then quantified using a correlation coefficient between empirical and modeled quantiles.

\section{b. Spatial variability}

We quantify the spatial structure of the rainfall field in terms of spatial correlations for all possible rain gauge pairs and for time scales ranging from 1 to $24 \mathrm{~h}$. The correlation $\hat{r}\left(d_{i j}\right)$ between two rainfall time series $R_{i}$ and $R_{j}$ measured at gauges $i$ and $j$ separated by distance $d_{i j}$ can be estimated using Pearson's product-moment estimator as 


$$
\hat{r}\left(d_{i j}\right)=\frac{\left\langle R_{i} R_{j}\right\rangle-\left\langle R_{i}\right\rangle\left\langle R_{j}\right\rangle}{\left(\left\langle R_{i}^{2}\right\rangle-\left\langle R_{i}\right\rangle^{2}\right)^{0.5}\left(\left\langle R_{j}^{2}\right\rangle-\left\langle R_{j}\right\rangle^{2}\right)^{0.5}},
$$

where \langle\rangle indicates the corresponding sample average. Pearson's product-moment estimator has been widely used to quantify the spatial correlation structure of rainfall (e.g., Ciach and Krajewski 2006; Moron et al. 2007; Villarini et al. 2008a; Mandapaka et al. 2009; Pedersen et al. 2010; Tokay and Öztürk 2012).

Habib et al. (2001) showed that Pearson's correlation estimates for non-Gaussian distributions are biased, and they proposed a simulation-based method to reduce the bias. Their approach is valid for data following a mixed log-normal distribution and therefore is not used in the current study. Some studies applied Box-Cox transformation ( $\log$ and square root are special cases) on the data to reduce the effects of skewness on estimated spatial statistics (e.g., Erdin et al. 2012). There are also studies that used "uncentered" correlations, in which the averages (e.g., $\left\langle R_{i}\right\rangle\left\langle R_{j}\right\rangle$ and $\left\langle R_{i}\right\rangle^{2}$ ) are not subtracted in the numerator and denominator of Eq. (3) (e.g., Zawadzki 1973; Germann and Zawadzki 2002). While interpretation of correlations from transformed data is not straightforward, uncentered correlation estimates are often inflated, leading to difficulties in their parameterization for small areas such as Singapore. For these reasons, all inferences regarding spatial structure in this study were based on a classical Pearson's estimator [Eq. (3)]. General trends in Pearson's correlation estimates were checked against square root-transformed and uncentered correlation estimates, however, wherever possible.

\section{Results and discussion}

As mentioned in the introduction, the gauge data that were available for this study were at hourly resolution. The hourly data were integrated to different time scales starting from 2 to $24 \mathrm{~h}$, and the corresponding rain rates in millimeters per hour were obtained. In total, we analyzed PDF and spatial structure of rain rates for eight time scales $(1,2,3,4,6,8,12$, and $24 \mathrm{~h})$ in this study.

\section{a. Probability distribution of rain rates}

Figure 4 shows the exceedance probabilities (or survival functions) of nonzero rain rates for six of eight time scales (hereinafter, the results for 3- and 6-h rain rates are not displayed in the figures for the sake of clarity, but they are presented in the tables). Note that the minimum nonzero rain rate in the hourly data is $0.1 \mathrm{~mm} \mathrm{~h}^{-1}$. When averaged to coarser time resolutions, the corresponding rain-rate series would have values smaller than

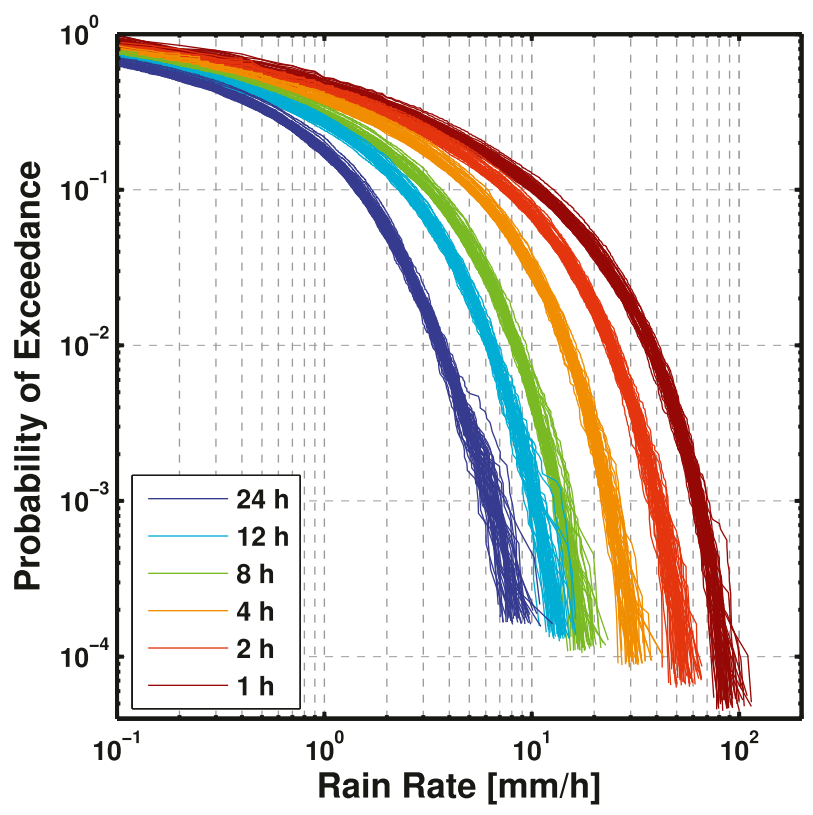

FIG. 4. Probability of exceedance (survival functions) of nonzero rain rates for six different time scales. Each curve represents the survival function estimated using data from a single rain gauge.

$0.1 \mathrm{~mm} \mathrm{~h}^{-1}$. To be specific, the minimum nonzero value would be $0.05 \mathrm{~mm} \mathrm{~h}^{-1}$ for a 2-h time scale and $0.1 / 24=$ $0.004167 \mathrm{~mm} \mathrm{~h}^{-1}$ in a daily rain-rate series. Each curve in Fig. 4 represents a survival function that was estimated by using nonzero data from a single rain gauge.

\section{1) L-MOMENT-BASED CHARACTERIZATION}

To characterize the PDF of rain rates at each time scale, we estimated their $L$ skewness $\tau_{3}$ and $L$ kurtosis $\tau_{4}$ using the procedure described in section 3a. In Fig. 5, we compare the empirical $\left(\tau_{3}, \tau_{4}\right)$ values with theoretical $\left(\tau_{3}, \tau_{4}\right)$ curves of three-parameter lognormal (LN3), generalized Pareto (GPA), Weibull (WEI), and Pearson type-3 (PE3) distributions. These distributions were selected as possible PDFs on the basis of the evidence from the literature (e.g., Kedem and Chiu 1987; Burgueño et al. 1994; Hanson and Vogel 2008; Villarini et al. 2008b). The selected theoretical distributions are positively skewed with a finite lower bound and consist of three parameters referred to as shape, scale, and location parameters (Table 1). For time scales of 3-24 h, the empirical $L$-moment ratios were found to be closer to the PE3 $L$-moment ratio curve (Fig. 5). For hourly and 2-hourly rain rates, the empirical $L$-moment ratios were found to lie between the PE3 and WEI curves. On the basis of Fig. 5, we selected PE3 distribution for 3-24-h rain rates. For shorter time scales of 1 and $2 \mathrm{~h}$, we tested both PE3 and WEI distributions. The corresponding parameters of the distributions were estimated using 


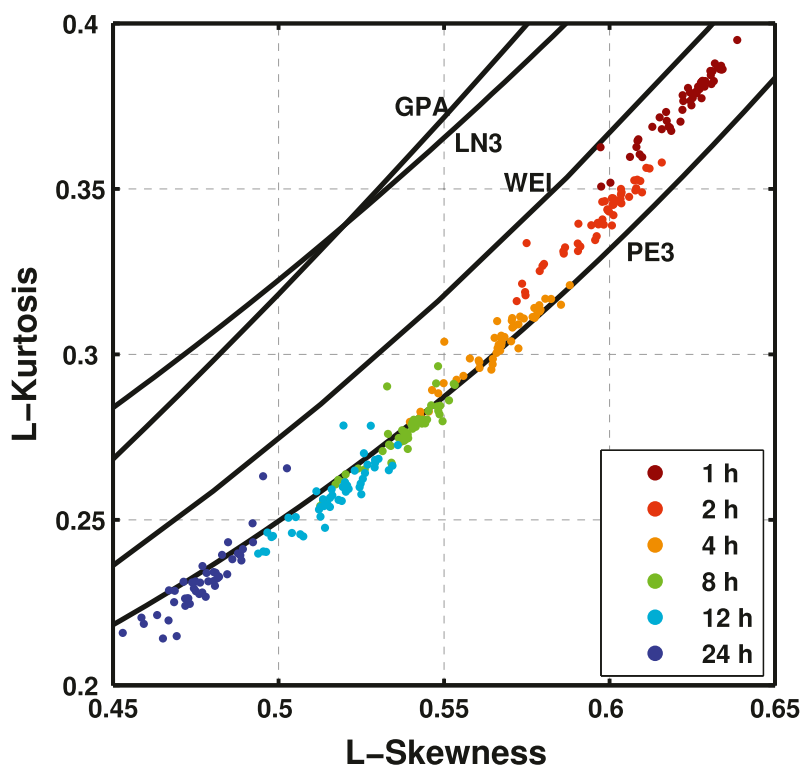

FIG. 5. Plot comparing the empirical $L$-moment ratios $(L$ skewness vs $L$ kurtosis) of rain rates with the theoretical $L$-moment ratio curves for six time scales. Each dot represents an $L$-moment ratio estimated using data from a single gauge.

equations given in section A.9 of Hosking and Wallis (1997).

Figure 6 shows the comparison of empirical and PE3 quantiles for six of eight time scales. Each curve in Fig. 6 represents a quantile-quantile (QQ) curve for a single gauge. Although hourly and 2-hourly rain rates were fitted with both PE3 and WEI distributions, we only show PE3 quantiles in Fig. 6 for the sake of clarity. In general, the quantiles of the fitted PE3 distribution match very well with those of observations for all gauges and time scales. However, the QQ curves deviate from the one-to-one line at very low and very high intensities. As the time scale increases, the bias at lower intensities decreases quickly, but the bias at upper tails persists up to $8 \mathrm{~h}$. For shorter time scales ( 1 and $2 \mathrm{~h}$ ), we also compared the observed quantiles with those of a fitted WEI distribution. The bias near the upper tail is higher for the WEI quantiles when compared with the PE3 ones (figure not shown).

We quantified the goodness of fit using the correlation between empirical and theoretical quantiles for each of the 49 rain gauges. The median value of correlation (from 49 values) varied from 0.987 at hourly scale to 0.994 at daily scale. Note that the correlations were estimated in linear space. When estimated in log-transformed scale (as in Fig. 6), the correlations were even higher. From Fig. 6 and high values of correlations, it can be concluded that the PE3 distribution provides a satisfactory fit to rain rates for all time scales that were considered in
TABLE 1. List of three-parameter probability distributions, with the shape parameter $k$, scale parameter $\alpha$, and location parameter $\xi$.

\begin{tabular}{cc}
\hline \hline Distribution & PDF \\
\hline GPA & $f(x)=\alpha^{-1} \exp [-(1-k) y]$, \\
& where $y=-k^{-1} \log [1-k(x-\xi) / \alpha], k \neq 0$ \\
WEI & $f(x)=\left[k y^{(k-1)} \exp \left(-y^{k}\right)\right] / \alpha$, \\
& where $y=(x-\xi) / \alpha$ \\
PE3 & $f(x)=y^{(k-1)} \exp (-k) /[\alpha \Gamma(k)]$, \\
& where $y=(x-\xi) / \alpha$ \\
LN3 & $f(x)=\exp \left(k y-y^{2} / 2\right) /\left[\alpha(2 \pi)^{1 / 2}\right]$, \\
& where $y=-k^{-1} \log [1-k(x-\xi) / \alpha], k \neq 0$ \\
\hline
\end{tabular}

this study. Table 2 lists the minimum, median, and maximum values of parameters of the PE3 distribution for each time scale.

We also tried to quantify the goodness of fit using a Kolmogorov-Smirnov (KS) test, but the KS test rejected the null hypothesis of a PE3 distribution because of the large sample sizes involved. When the sample size is very large (20000-25000 for hourly scale in this study), even small differences between empirical and theoretical distributions would lead to rejection of the null hypothesis. This sensitivity of the KS test to large sample size has also been reported in other studies (e.g., Villarini et al. 2008b). To gain confidence in the results, however, we conducted a simulation experiment and generated an ensemble of $200 \mathrm{PE} 3$ realizations for each gauge using the parameters obtained above (Table 2). Each realization of the ensemble was then fitted with the PE3 distribution, and the corresponding QQ curve was obtained. The ensemble QQ curves were then compared with the empirical ones from Fig. 6 for each gauge and time scale. The empirical QQ curve of each gauge was found to lie within the narrow band formed by the ensemble QQ curves (except for extreme values), reaffirming that the PE3 distribution provides a good fit to rain rates.

\section{2) TEMPORAL AND SPATIAL VARIATION OF PARAMETERS}

The variation of the shape, scale, and location parameters of the fitted PE3 distribution with time scale is shown in Fig. 7. The shape parameter increases with time scale, whereas the scale and location parameters decrease with it. It can be seen from Fig. 7 that the behavior of parameters with time scale can be parameterized in the form of simple power laws. Note that the vertical bar for each parameter and each time scale in Fig. 7 indicates gauge-to-gauge (or spatial) variability of parameters of the fitted PE3 distribution. For instance, the spatial variability in shape parameter increases with an increase in time scale. On the other hand, the spatial 


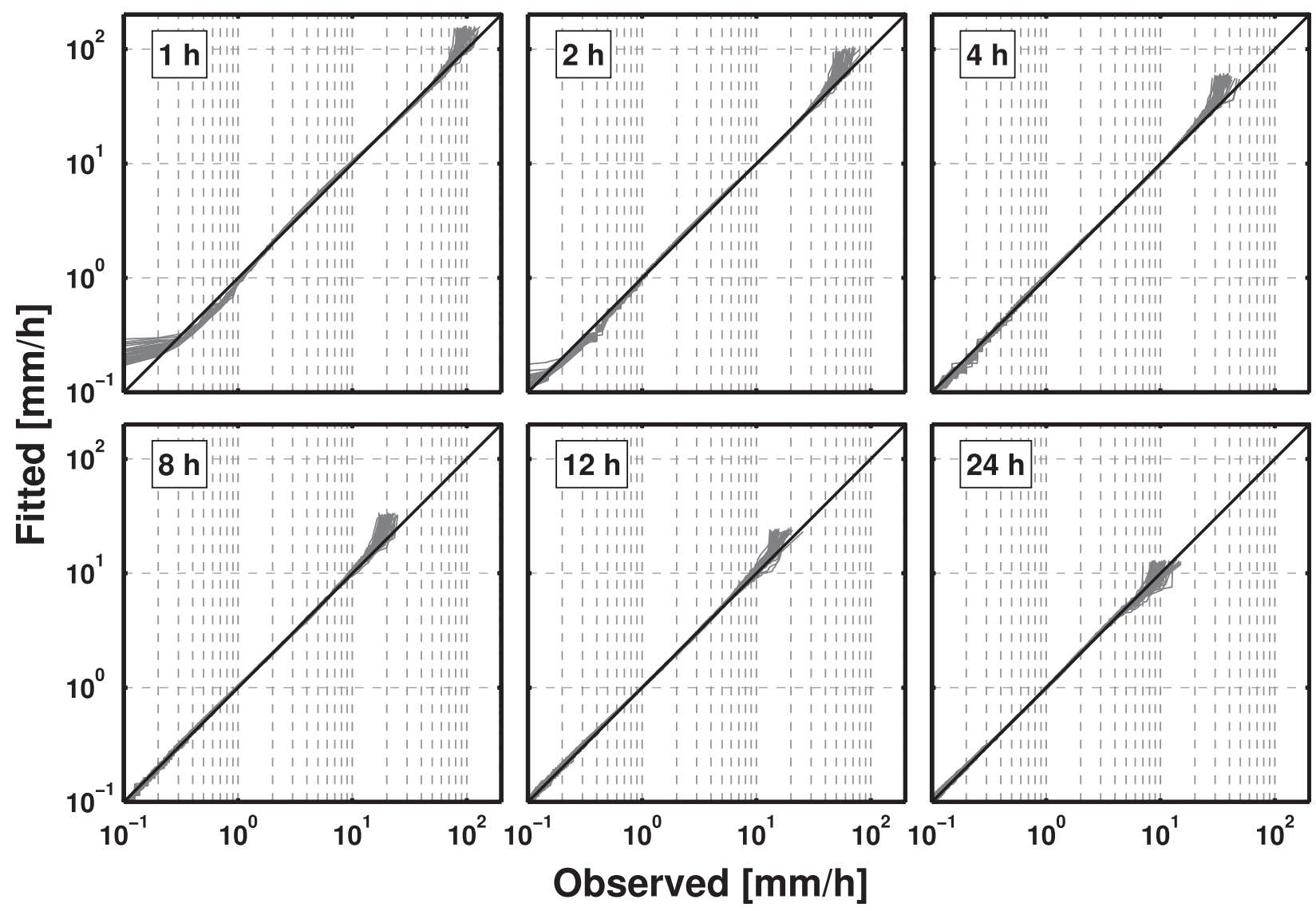

FIG. 6. Plot comparing quantiles of nonzero rain rates with those obtained from a fitted (Pearson type 3) distribution for each gauge and six time scales.

variability in scale and location parameters decreases with an increase in time scale. We also investigated the presence of any spatial trend in PE3 parameters by plotting contours of parameter values for each time scale. We did not notice significant spatial trends in parameter values (see Figs. S1 and S2 in the supplemental-material package at the Journals Online website: http://dx.doi.org/ 10.1175/JAMC-D-13-0115.s1).

\section{3) REMARKS ON ZERO-RAIN THRESHOLD}

As mentioned in section 2, some of the gauges in our network have a precision of $0.1 \mathrm{~mm}$ and the remaining ones have a precision of $0.2 \mathrm{~mm}$. The PDF analysis carried out to this point was based on a zero-rain threshold of $0.1 \mathrm{~mm} \mathrm{~h}^{-1}$ applied to hourly rain rates. We repeated the PDF analysis for a new zero-rain

TABLE 2. Minimum, median, and maximum values of $k, \alpha$, and $\xi$ parameters of the Pearson type-3 (see Table 1) distribution fitted to rain rates for different time scales.

\begin{tabular}{|c|c|c|c|c|c|c|c|c|c|}
\hline \multirow[b]{2}{*}{ Time scale (h) } & \multicolumn{3}{|c|}{$k$} & \multicolumn{3}{|c|}{$\alpha$} & \multicolumn{3}{|c|}{$\xi$} \\
\hline & Min & Median & $\operatorname{Max}$ & Min & Median & $\operatorname{Max}$ & Min & Median & Max \\
\hline 1 & 0.22 & 0.24 & 0.27 & 13.38 & 14.91 & 16.08 & 0.17 & 0.19 & 0.29 \\
\hline 2 & 0.25 & 0.27 & 0.30 & 8.59 & 9.48 & 10.31 & 0.09 & 0.10 & 0.17 \\
\hline 3 & 0.27 & 0.29 & 0.33 & 6.47 & 7.05 & 7.69 & 0.06 & 0.07 & 0.12 \\
\hline 4 & 0.28 & 0.31 & 0.35 & 5.16 & 5.58 & 6.06 & 0.04 & 0.05 & 0.09 \\
\hline 6 & 0.30 & 0.33 & 0.38 & 3.75 & 4.06 & 4.41 & 0.02 & 0.03 & 0.07 \\
\hline 8 & 0.33 & 0.35 & 0.40 & 2.79 & 3.06 & 3.25 & 0.02 & 0.02 & 0.05 \\
\hline 12 & 0.36 & 0.39 & 0.43 & 2.02 & 2.19 & 2.37 & 0.01 & 0.01 & 0.04 \\
\hline 24 & 0.42 & 0.47 & 0.54 & 1.04 & 1.16 & 1.23 & 0.00 & 0.00 & 0.02 \\
\hline
\end{tabular}



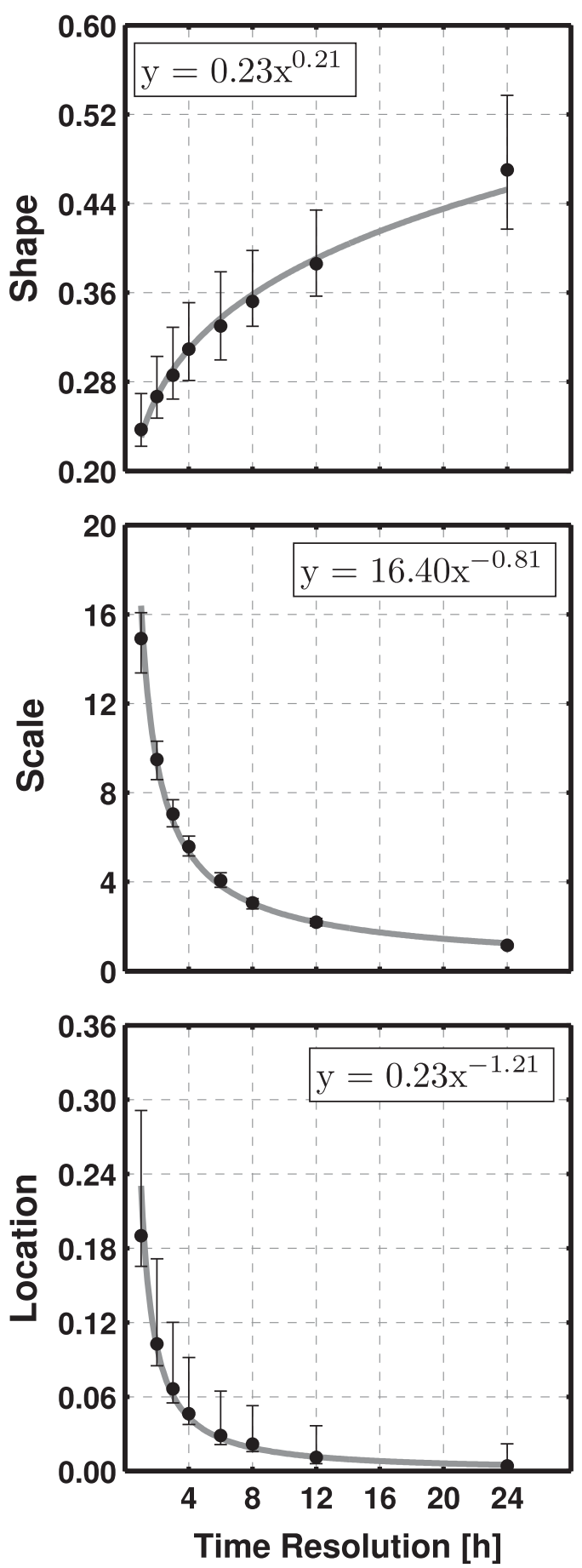

FIG. 7. Parameters (location, scale, and shape) of the Pearson type-3 distribution fitted to nonzero rates at different time resolutions. The vertical bars represent intergauge variability in parameters. The power laws shown in each panel were fitted to the median values of parameters.

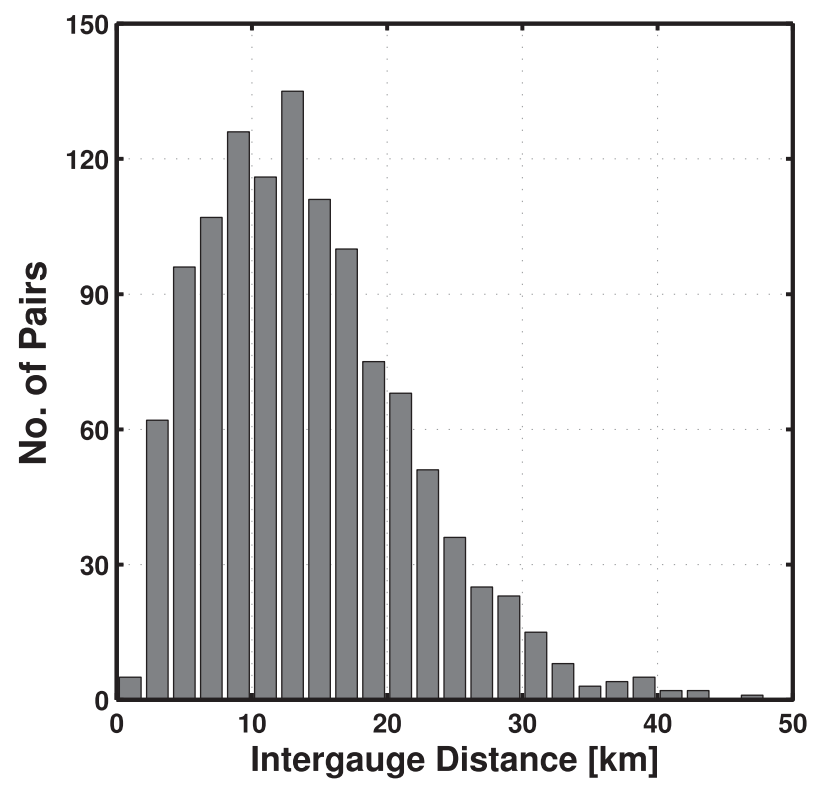

FIG. 8. Distribution of intergauge distances for the gauge network shown in Fig. 1.

threshold of $0.2 \mathrm{~mm} \mathrm{~h}^{-1}$. All of the hourly time steps at which rain rates are $<0.2 \mathrm{~mm} \mathrm{~h}^{-1}$ were set to zero. The hourly data were then integrated to obtain rain rates at other time scales $(2-24 \mathrm{~h})$. The new minimum possible rain rate at 2 -h scale is $0.2 / 2=0.1 \mathrm{~mm} \mathrm{~h}^{-1}$, and for daily scale it is $0.2 / 24=0.00833 \mathrm{~mm} \mathrm{~h}^{-1}$. The PE3 distribution was found to be the best fit for the gauge series with a nonzero threshold of $0.2 \mathrm{~mm} \mathrm{~h}^{-1}$. The parameters were slightly different when compared with those obtained for a threshold of $0.1 \mathrm{~mm} \mathrm{~h}^{-1}$, however. The effect of the zero-rain threshold was noticed mainly in the location parameter and for shorter time scales (1-2h). The effect of the zero-rain threshold on the PDF characterization was not significant for coarser resolutions.

\section{b. Spatial correlations}

The spatial structure of annual, seasonal, and monthly rainfall totals in Singapore in the form of isohyetal curves has been well documented by many studies (Watts 1955; Chia and Foong 1991; Fong 2012). In this study, we describe the spatial structure of rainfall at short time scales (i.e., 1-24 h) using intergauge correlations. The rain gauge network consists of 49 gauges in an area of $\sim 710 \mathrm{~km}^{2}$ and covers a wide range of intergauge distances, varying from 0.8 to $46 \mathrm{~km}$ with an average value of $14.1 \mathrm{~km}$ (Figs. 1 and 8). The network has a sufficient number of gauge pairs at smaller and larger intergauge distances to robustly characterize the decreasing trend of correlations with distance. For instance, there are more than 150 gauge pairs in the distance group 2-6 km and about 50 pairs with distances between 26 and 


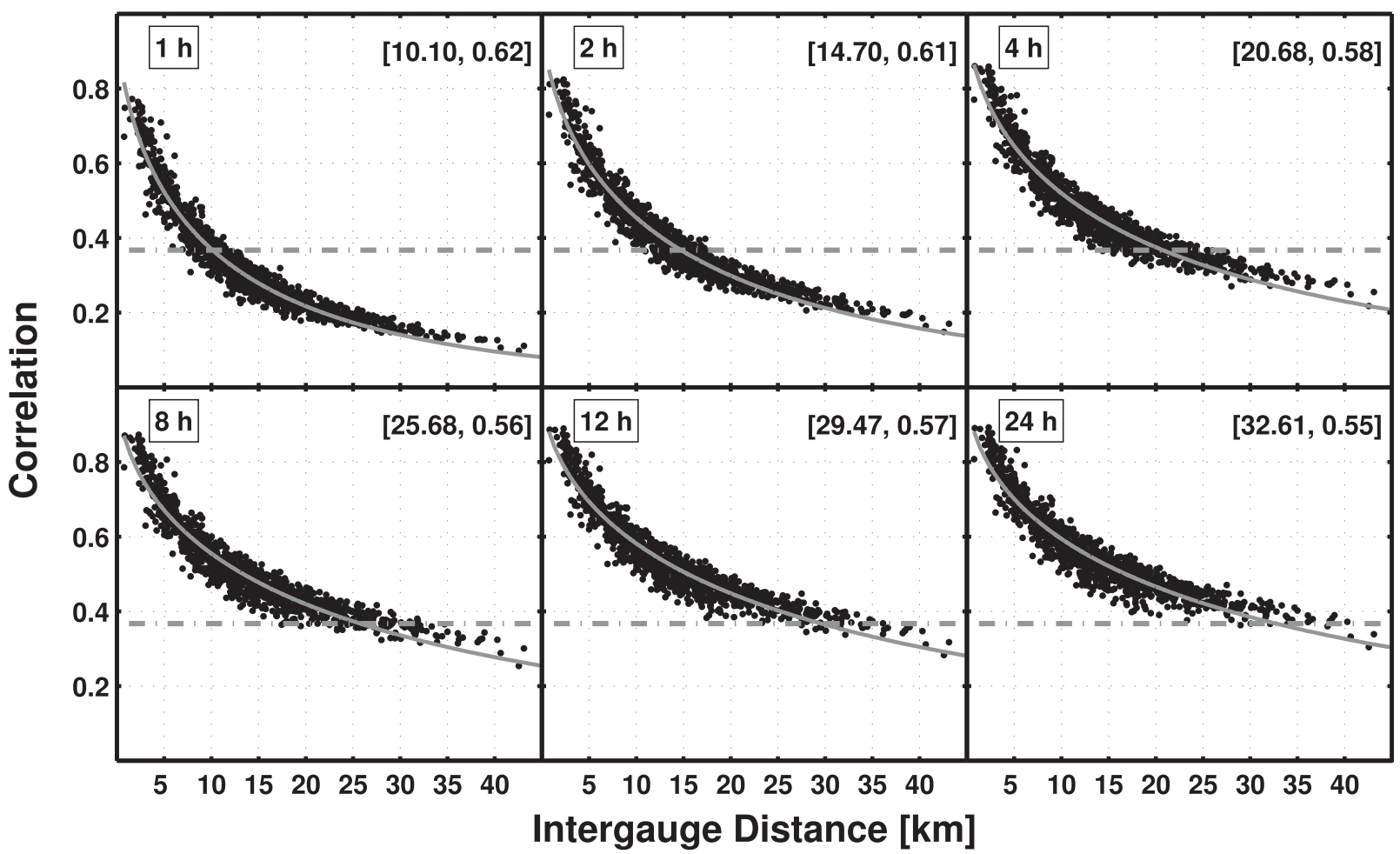

FIG. 9. Spatial correlations [Eq. (3)] for each gauge pair plotted against the corresponding intergauge distance. The solid gray line represents the two-parameter exponential function [Eq. (4)] fitted to the correlations. The parameters (correlation distance and exponent) of the fitted function are shown in each panel.

$30 \mathrm{~km}$ (Fig. 8). First, we analyze spatial structure assuming isotropy (correlations dependent only on the intergauge distance and not on the direction) and temporal stationarity (correlations independent of time of the day or year). We refer to this analysis as unconditional isotropic analysis. We then stratify the data according to month of the year, time of the day, and gauge-pair orientation to investigate monthly, diurnal, and directional dependence (anisotropy) of spatial correlation structure.

\section{1) UNCONDITIONAL ISOTROPIC ANALYSIS}

This section presents correlations (estimated from the entire data) as a function of only the intergauge distance. Figure 9 shows the variation of Pearson's correlation estimates with the intergauge distance for time scales ranging from 1 to $24 \mathrm{~h}$. Consistent with other studies carried out elsewhere in the world (e.g., Huff and Shipp 1969; Stol 1972; Berndtsson 1988; Bidin and Chappell 2003; Krajewski et al. 2003; Villarini et al. 2008a), the correlations decreased with increasing intergauge distance and increased with increasing time scale. We parameterized the decreasing trend of correlations for each time scale using a powered-exponential function of the following form:

$$
\hat{r}\left(d_{i j}\right)=\exp \left[-\left(\frac{d_{i j}}{d_{c}}\right)^{s}\right] d_{c}>0, \quad 0 \leq s \leq 2,
$$

where $d_{i j}$ is the distance between two gauges $i$ and $j, d_{c}$ is the $e$-folding correlation distance defined as the distance at which the correlation drops to $1 / e(\sim 0.367)$, and exponent $s$ characterizes the rate of decrease of correlation with intergauge distance. Equation (4) is a variant of the three-parameter (correlation distance, exponent, and nugget parameter) exponential function that was used by several studies to model the spatial correlation structure of rainfall (e.g., Krajewski et al. 2003; Ciach and Krajewski 2006; Villarini et al. 2008a; Mandapaka et al. 2009; Tokay and Öztürk 2012). The nugget parameter quantifies the gauge measurement error and microscale variability of the process. We did not include the nugget parameter in Eq. (4) because the gauge network is not dense enough for its estimation.

The parameter $d_{c}$ characterizes the smoothness of the field and can take any positive value. A smaller value of $d_{c}$ implies a more spatially variable process. The exponent $s$ can only take values between 0 and 2. Equation (4) simplifies to an exponential function for $s$ equal to 1 and to a Gaussian function for $s$ equal to 2. A smaller value 
TABLE 3. Parameters of the powered-exponential function [Eq. (4)] fitted to the correlation estimates for different time scales.

\begin{tabular}{ccc}
\hline \hline Time scale $(\mathrm{h})$ & Correlation distance $(\mathrm{km})$ & Exponent \\
\hline 1 & 10.10 & 0.62 \\
2 & 14.70 & 0.62 \\
3 & 18.27 & 0.60 \\
4 & 20.68 & 0.58 \\
6 & 24.88 & 0.57 \\
8 & 25.68 & 0.56 \\
12 & 29.47 & 0.57 \\
24 & 32.61 & 0.55 \\
\hline
\end{tabular}

of $s$ indicates rapid decay at intergauge distances smaller than $d_{c}$ and slow decay at larger scales. The fitted correlation functions for each time scale are shown in Fig. 9. It can be seen that the decreasing pattern of correlations with intergauge distance can be described well by the powered-exponential function. The parameters of the fitted correlation functions for all time scales of concern are listed in Table 3 . The value of $d_{c}$ varies from $10.1 \mathrm{~km}$ at hourly scale to $32.6 \mathrm{~km}$ at daily scale.

The spatial correlation structure is influenced by the local climatic regime. For instance, Ha et al. (2007) reported summertime $d_{c}$ values ranging from 47 to $102 \mathrm{~km}$ for hourly accumulations in the Korean Peninsula. Villarini et al. (2008a) reported $d_{c}$ of $\sim 40 \mathrm{~km}$ at hourly scale and $145 \mathrm{~km}$ at daily scale in the southwestern United Kingdom. Mandapaka et al. (2009) found the $d_{c}$ value to be $40 \mathrm{~km}$ for warm-season hourly accumulations in Oklahoma. Relative to values in such midlatitude regions, the values of $d_{c}$ obtained in the current study are much smaller, indicating the high spatial variability and localized nature of rainfall in Singapore. On the other hand, the correlation functions from the current study are comparable to those shown in Krajewski et al. (2003) for the tropical regions of Florida and Brazil.

The rapid increase in $d_{c}$ up to a time scale of $\sim 6 \mathrm{~h}$ and the slow rise thereafter (Fig. 10) show that the effect of temporal integration on smoothness of rainfall patterns is larger at shorter time scales. The temporal variation of $s$ (from 0.62 at hourly scale to 0.55 at daily scale) is not as smooth as the correlation distance (see Table 3). Similar temporal trends were observed in $d_{c}$ and $s$ obtained from square root-transformed data and uncentered correlations; the absolute values were higher relative to those in Table 3, however. As in section $4 \mathrm{a}(3)$, we also analyzed the effect of zero-rain threshold on spatial correlations. The $d_{c}$ obtained for the gauge data with a zero-rain threshold of $0.2 \mathrm{~mm} \mathrm{~h}^{-1}$ varied from $10.09 \mathrm{~km}$ at hourly scale to $32.49 \mathrm{~km}$ for daily scale. On comparing these values with those in Table 3, we can say that the effect of zero-rain threshold on the correlation analysis is negligible. This result is expected because the correlation

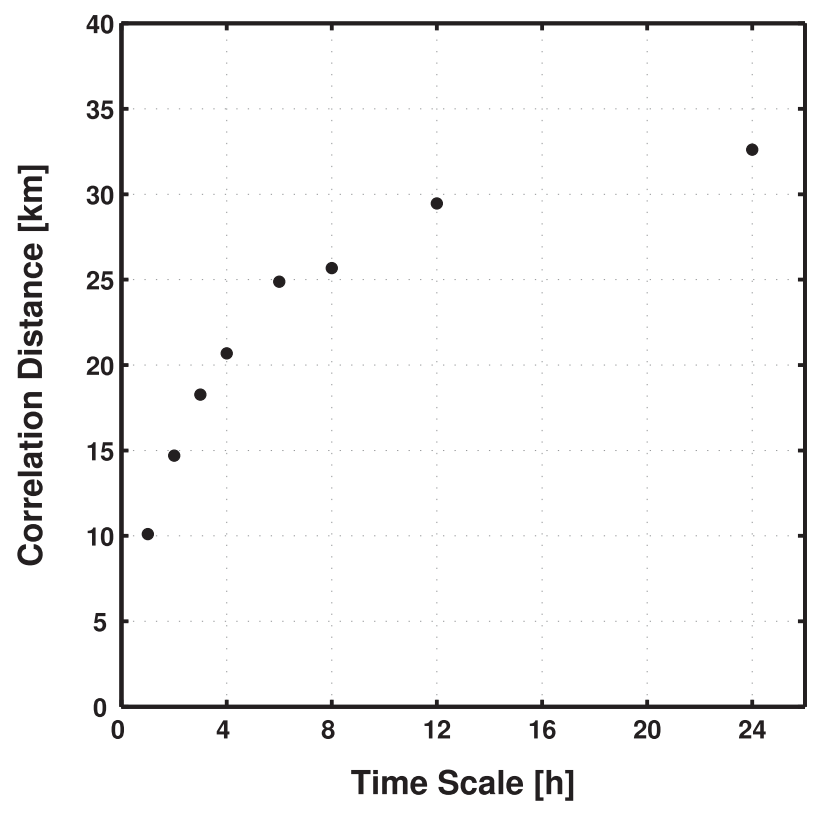

FIG. 10. Variation of correlation distance with the integration time scale.

analysis was performed for the full series (including zeros) whereas PDF analysis was limited to nonzero rain rates.

\section{2) MONTHLY AND DIURNAL VARIATION OF SPATIAL CORRELATIONS}

To understand monthly variation in spatial structure, we estimated spatial correlations for each month separately. Note that the emphasis was still on short-term (1-24 h) rain rates, but they were stratified according to each month. Similar to unconditional analysis, we parameterized the decreasing trend of spatial correlations using Eq. (4). Figure 11 shows the monthly variation of $d_{c}$ for five different time scales (see Table 4 for the other three time scales). On some occasions (e.g., in January for time scale $>6 \mathrm{~h}$ ), the estimated $d_{c}$ value exceeds $50 \mathrm{~km}$. These values must be taken with caution because the fitted correlation functions might be affected by decreasing sample sizes at longer intergauge distances. The monthly signal of $d_{c}$ displays three distinct peaks: a primary peak during December-January and two secondary peaks in March and June-July (Fig. 11 and Table 4). In a similar way, three troughs can be seen in the monthly pattern of $d_{c}$ : a primary minimum during April and two secondary minima in February and September-October. From the monthly signal of $d_{c}$, it can be inferred that the rainfall patterns are widespread during December-January and are most variable during April. The results are in agreement with Bidin and Chappell (2003), who reported larger spatial correlations during the northeast monsoon than during the 


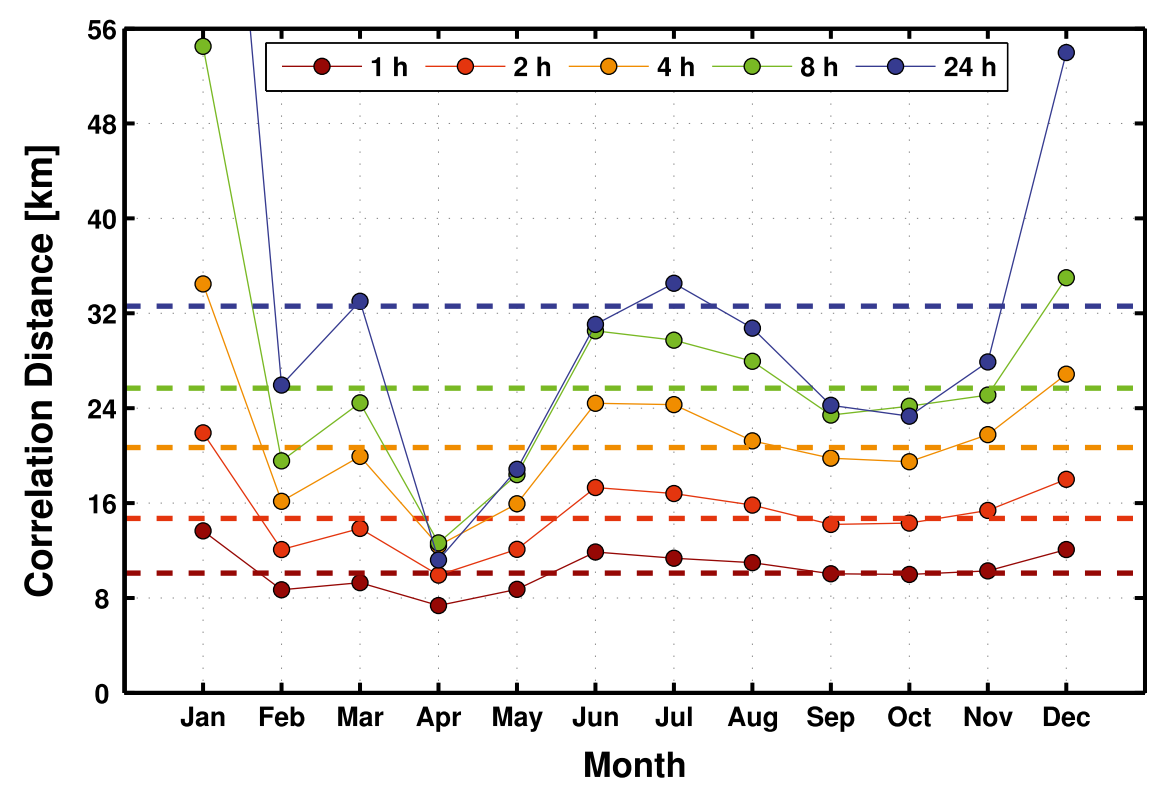

FIG. 11. Monthly variation of the $e$-folding correlation distance for the time scales of $1,2,4,8$, and $24 \mathrm{~h}$. The $e$-folding distance obtained by pooling all months is shown by the dashed lines.

southwest monsoon, although for seasonal rainfall totals. The second parameter in Eq. (4) (the exponent $s$ ) did not display a strong monthly pattern: its values ranged from 0.58 to 0.67 for hourly scale and from 0.53 to 0.67 for daily scale.

The monthly variation observed in Fig. 11 can be better described using synoptic-scale weather patterns. Larger values of $d_{c}$ during December-January are a reflection of widespread moderate- to high-intensity rainfall caused by synoptic-scale disturbances such as cold surges and associated strong northeasterly winds during the first half (December and January) of the northeast monsoon (e.g., Chang et al. 2005; Tangang et al. 2008; Fong 2012). The number of cold surges is significantly lower in the second half of the northeast monsoon (e.g., Chang et al. 2005), thus decreasing the amount of rainfall as well as the spatial smoothness, as seen in the sudden drop of $d_{c}$ in February (Fig. 11). During the intermonsoon months of April and October, the upperlevel winds are weak and variable and the convection is at its greatest, often leading to afternoon showers (e.g., Watts 1955; Chia and Foong 1991; Fong 2012). This characteristic can be observed in the form of low values of $d_{c}$ during April and October (Fig. 11).

To understand the diurnal variation in spatial patterns of rainfall, we stratified hourly rain rates according to the time of the day and estimated spatial correlations. The correlations were then fitted using the poweredexponential function [Eq. (4)]. Figure 12 shows diurnal variation in the $e$-folding correlation distance $d_{c}$. The value of $d_{c}$ varies from $7.7 \mathrm{~km}$ at 1900 local time to
$22.5 \mathrm{~km}$ at 0200 local time. Higher values of $d_{c}$ between 0100 and 0600 and lower values between 1500 and 1900 indicate that the rainfall patterns are smoothest during the predawn hours and most variable in the afternoon. It is also interesting to note that the unconditional (pooled in) $d_{c}$ value of $10.1 \mathrm{~km}$ is closer to the afternoon $d_{c}$ values, which shows that unconditional spatial correlations are mainly defined by the afternoon rainfall patterns. We also analyzed monthly variation in the diurnal cycle of spatial correlations. Separating the data into each month and hour reduced the sample size available for estimating correlations and led to noisy estimates, in particular during the morning hours of some months. The

TABLE 4. Monthly variation of the $e$-folding correlation distance $(\mathrm{km})$ obtained by fitting a powered-exponential function [Eq. (4)] to correlation estimates at different time scales.

\begin{tabular}{lrrrccccc}
\hline \hline & \multicolumn{8}{c}{ Time scale (h) } \\
\cline { 2 - 9 } Month & \multicolumn{1}{c}{1} & \multicolumn{1}{c}{2} & 3 & 4 & 6 & 8 & 12 & 24 \\
\hline Jan & 13.66 & 21.92 & 28.76 & 34.48 & 47.04 & 54.51 & 66.23 & 101.46 \\
Feb & 8.70 & 12.08 & 15.60 & 16.14 & 21.89 & 19.56 & 26.47 & 25.96 \\
Mar & 9.29 & 13.87 & 16.76 & 19.94 & 25.44 & 24.46 & 31.37 & 33.01 \\
Apr & 7.36 & 9.92 & 11.91 & 12.41 & 13.52 & 12.64 & 13.74 & 11.20 \\
May & 8.73 & 12.11 & 15.15 & 15.93 & 19.01 & 18.39 & 20.12 & 18.84 \\
Jun & 11.87 & 17.31 & 19.61 & 24.41 & 28.16 & 30.52 & 28.19 & 31.06 \\
Jul & 11.35 & 16.80 & 19.97 & 24.29 & 26.84 & 29.74 & 29.28 & 34.53 \\
Aug & 10.98 & 15.82 & 19.28 & 21.24 & 24.37 & 27.96 & 26.32 & 30.74 \\
Sep & 10.03 & 14.19 & 17.73 & 19.78 & 22.50 & 23.42 & 24.41 & 24.24 \\
Oct & 9.97 & 14.31 & 18.06 & 19.48 & 22.47 & 24.17 & 25.39 & 23.32 \\
Nov & 10.28 & 15.37 & 19.06 & 21.77 & 26.38 & 25.11 & 29.29 & 27.89 \\
Dec & 12.07 & 18.00 & 23.13 & 26.87 & 32.40 & 34.99 & 44.60 & 53.98 \\
\hline
\end{tabular}




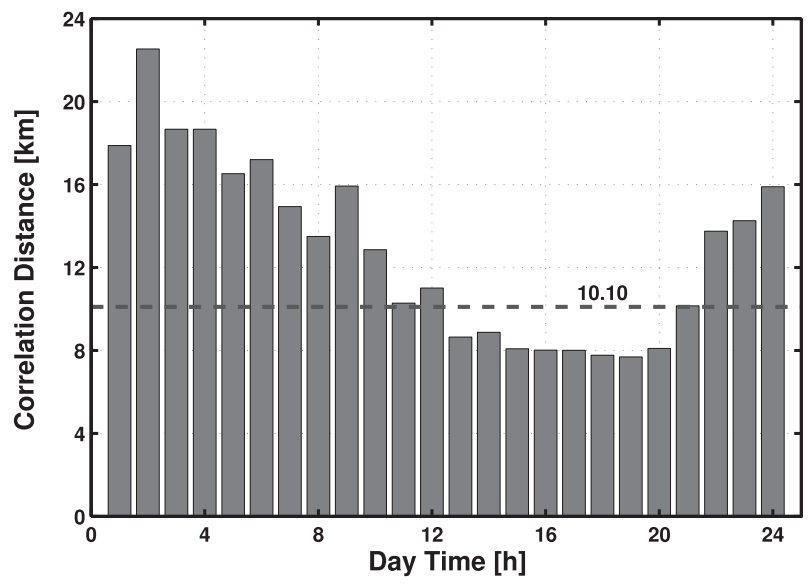

FIG. 12. Diurnal variation of the $e$-folding correlation distance. The $e$-folding distance obtained by pooling all hours is shown by the dashed line.

general pattern of the diurnal cycle (predawn maximum and an afternoon minimum) remained the same during all months (figure not shown), however, except for the differences in the magnitude of $d_{c}$.

\section{3) ChARACTERIZING ANiSOTROPY}

To this point, the analysis of spatial structure was based on the assumption that correlation structure is isotropic. To understand the directional dependence of the spatial correlations, we mapped them in a two-dimensional space of intergauge distances. To be specific, each $\hat{r}\left(d_{i j}\right)$ was assigned a location in a polar map of intergauge distances on the basis of $d_{i j}$ and its orientation with north. Since $\hat{r}\left(d_{i j}\right)=\hat{r}\left(d_{i i}\right)$, the above polar map of correlations is symmetric about its origin. Many studies have used such two-dimensional correlation maps to quantify anisotropy in rainfall (e.g., Sharon 1978; Berndtsson 1988; Sumner and Bonell 1988; Velasco-Forero et al. 2009). Figure 13 shows contours obtained from the correlation estimates embedded in a two-dimensional space. Note that only the intergauge distances up to $35 \mathrm{~km}$ are shown in Fig. 13 instead of the maximum possible distance of $46 \mathrm{~km}$ that is shown in Fig. 8. This is because of noise in the correlation contours at longer separation distances.

For all time scales, the spatial gradients in correlations were found to be dependent on the direction of the
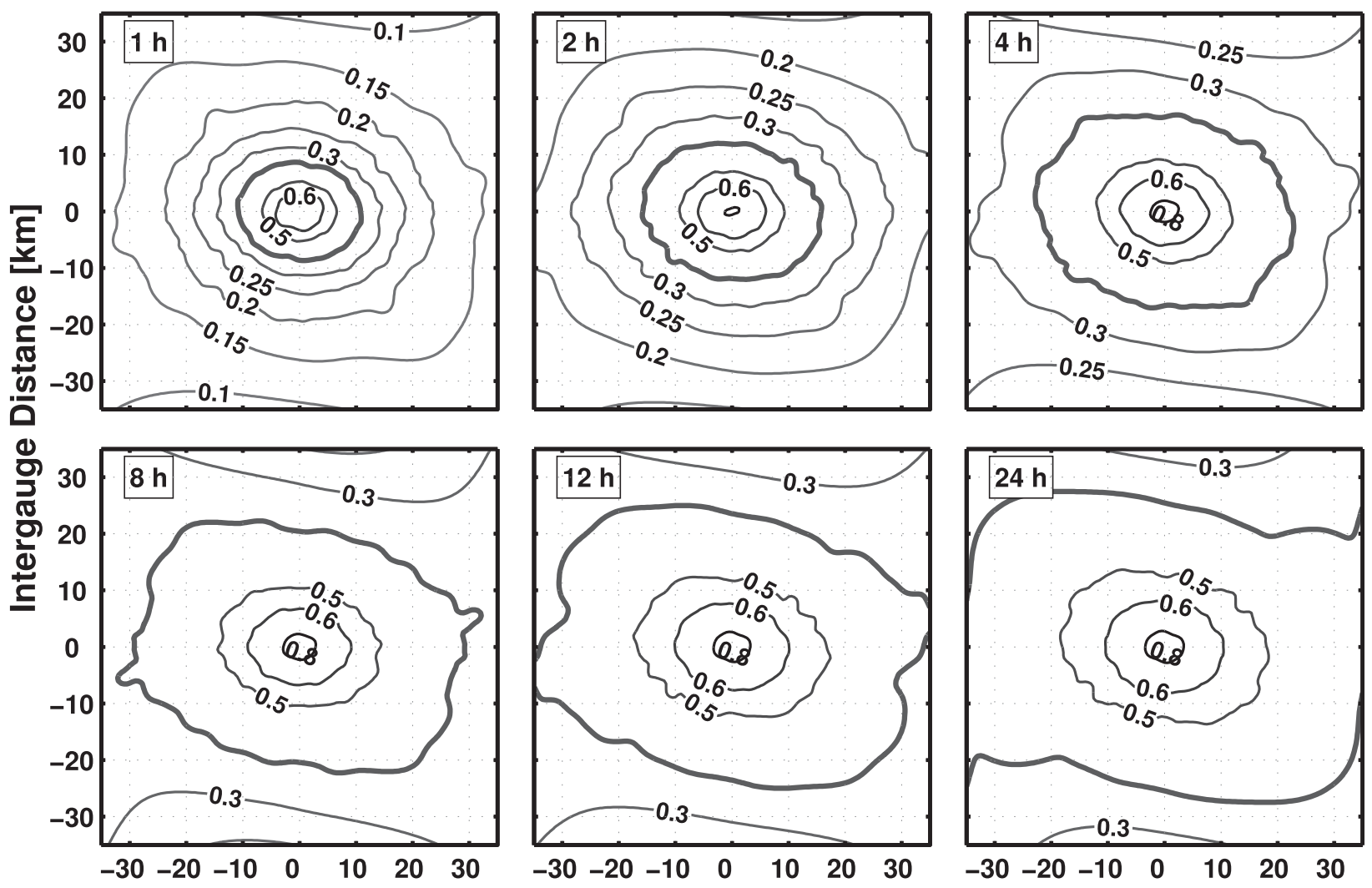

Intergauge Distance [km]

FIG. 13. Contours representing isocorrelation lines in the two-dimensional space of intergauge distances for six time scales. The distance is considered positive in the west-east and south-north directions and negative otherwise. The thick gray line represents the 0.367 (1/e) correlation contour. 
gauge pair, suggesting pronounced anisotropy (Fig. 13). The contours are elliptical in shape, except for lower correlations, when they are approximately rectangular. We quantified anisotropy by fitting ellipse to the correlation contours. The parameterization in the form of ellipse was done only when the contours are enclosed within the domain of $[-25,25] \mathrm{km}$ in the north-south and east-west directions. The $25-\mathrm{km}$ condition was necessary to avoid fitting an ellipse to nonelliptical shapes (e.g., the 0.367 contour in the bottom-left panel of Fig. 13). From the fitted ellipse, we obtained the lengths of the semimajor axis $a$ and the semiminor axis $b$, the orientation $\theta$ of the major axis with the north, and the eccentricity, defined as $e=\left[1-(b / a)^{2}\right]^{0.5}$.

First, we compare $a$ and $b$ values of the 0.367 contour with $d_{c}$ of section $4 \mathrm{a}(1)$. In the presence of anisotropy, $a$ and $b$ values of the 0.367 contour are such that $b<d_{c}<a$. For the hourly scale, the $d_{c}$ value of $10.1 \mathrm{~km}$ lies between $b$ and $a$ values of 8.6 and $10.8 \mathrm{~km}$, respectively. In a similar way, $b(=17.1 \mathrm{~km})<$ $d_{c}(=20.7 \mathrm{~km})<a(=22.8 \mathrm{~km})$ for 4 -h rain rates. Note, however, that a comparison of $a$ and $b$ with $d_{c}$ is possible only for time scales for which the 0.367 contour was fitted with an ellipse. For example, 0.367 contours of longer $(>4 \mathrm{~h})$ time scales were not fitted with an ellipse because they did not satisfy the $25-\mathrm{km}$ condition discussed in the previous paragraph. Therefore, the focus hereinafter will be on the orientation and eccentricity of multiple correlation (0.2-0.6) contours that were fitted with an ellipse. On average, the orientation of the fitted ellipse was found to be $99^{\circ}$ relative to north, with an eccentricity of 0.64 . The results showed considerable dependence of $\theta$ on the spatial scale, however. The value of $\theta$ ranged from $85.7^{\circ}$ to $96.4^{\circ}$ for smaller spatial scales $(a<10 \mathrm{~km})$, and from $101.2^{\circ}$ to $106.5^{\circ}$ for larger scales $(a>20 \mathrm{~km})$. The scale dependence in $e$ was not as pronounced as in $\theta$; $e$ was found to be in the range of $0.61-0.65$ for $a<10 \mathrm{~km}$, and $0.59-0.71$ for $a>20 \mathrm{~km}$.

To gain further insight into the temporal variability of anisotropy, we partitioned the data according to the month of the year and obtained correlation contours. Figure 14 shows the monthly variation of correlation contours for hourly rain rates. The spatial gradients in correlations and the orientation of contours changed considerably from month to month. To better quantify the monthly variation, we fitted an ellipse to each contour enclosed within the $[-25,25]$ box and obtained $a, b$, $\theta$, and $e$. As expected, $a$ and $b$ displayed monthly variation similar to that of $d_{c}$ (Fig. 11), as discussed in section $4 \mathrm{~b}(2)$. In Fig. 15, we show monthly behavior of $\theta$ for four different correlation contours. The average value of $\theta$ varies from $\sim 55^{\circ}$ in August to $\sim 130^{\circ}$ in February. From Fig. 15, it can be concluded that the rainfall patterns are aligned in a west-northwest (WNW) to east-southeast (ESE) direction $\left(100^{\circ}<\theta<130^{\circ}\right)$ from November to March and in a west-southwest (WSW) to east-northeast (ENE) direction $\left(55^{\circ}<\theta<80^{\circ}\right)$ from June to September. During the intermonsoon months of April, May, and October, the rainfall patterns were found to be approximately east-west oriented $\left(\theta \sim 90^{\circ}\right)$. The values of $e$ were lower (0.57-0.59) during the months of January and July, and higher (0.71-0.77) during February and October. The monthly variation of anisotropy was found to be similar for other time scales $(2-24 \mathrm{~h})$.

A thorough understanding of the physical mechanisms behind observed monthly, diurnal, and directional patterns in spatial correlation structure requires a rigorous quantitative analysis linking rainfall structure to synoptic (e.g., cold surges) and subsynoptic (e.g., landsea breezes) patterns. Furthermore, a storm-scale investigation is necessary to understand the physical mechanisms responsible for the scale dependence of rainfall anisotropy. Such analyses are beyond the scope of this study.

\section{Concluding remarks}

We analyzed data from a dense rain gauge network in Singapore to characterize various statistical features of equatorial rainfall. The rain-rate distributions for time scales varying from 1 to $24 \mathrm{~h}$ were identified using the $L$-moment approach. The spatial coherence was quantified using intergauge correlations. The spatial correlation structure was analyzed first by using an isotropic (directional independence) assumption. The monthly and diurnal patterns of isotropic correlations were quantified using the variation of correlation distance. The isotropy assumption was then relaxed to study the dependence of spatial correlations on gauge-pair orientation. The main conclusions of this study are as follow:

1) The Pearson type- 3 distribution proved to be the best fit for rain rates at all time scales of concern. The parameters of the fitted PE3 distribution displayed power-law behavior with time scale.

2) The isotropic spatial correlation analysis showed that the correlation distance varied from $10 \mathrm{~km}$ at the hourly scale to $33 \mathrm{~km}$ at the daily scale. Significant monthly and diurnal variability was observed in $d_{c}$. The rainfall patterns were found to be smoothest during the first half (December-January) of the northeast monsoon and most variable during the intermonsoon months of April and October. In addition, the rainfall patterns were most variable in the afternoon hours (1500-1900), with a $d_{c}$ value around $8 \mathrm{~km}$, and smoothest for the early hours $(0100$ and 0600), with a $d_{c}$ value between 17 and $23 \mathrm{~km}$. 

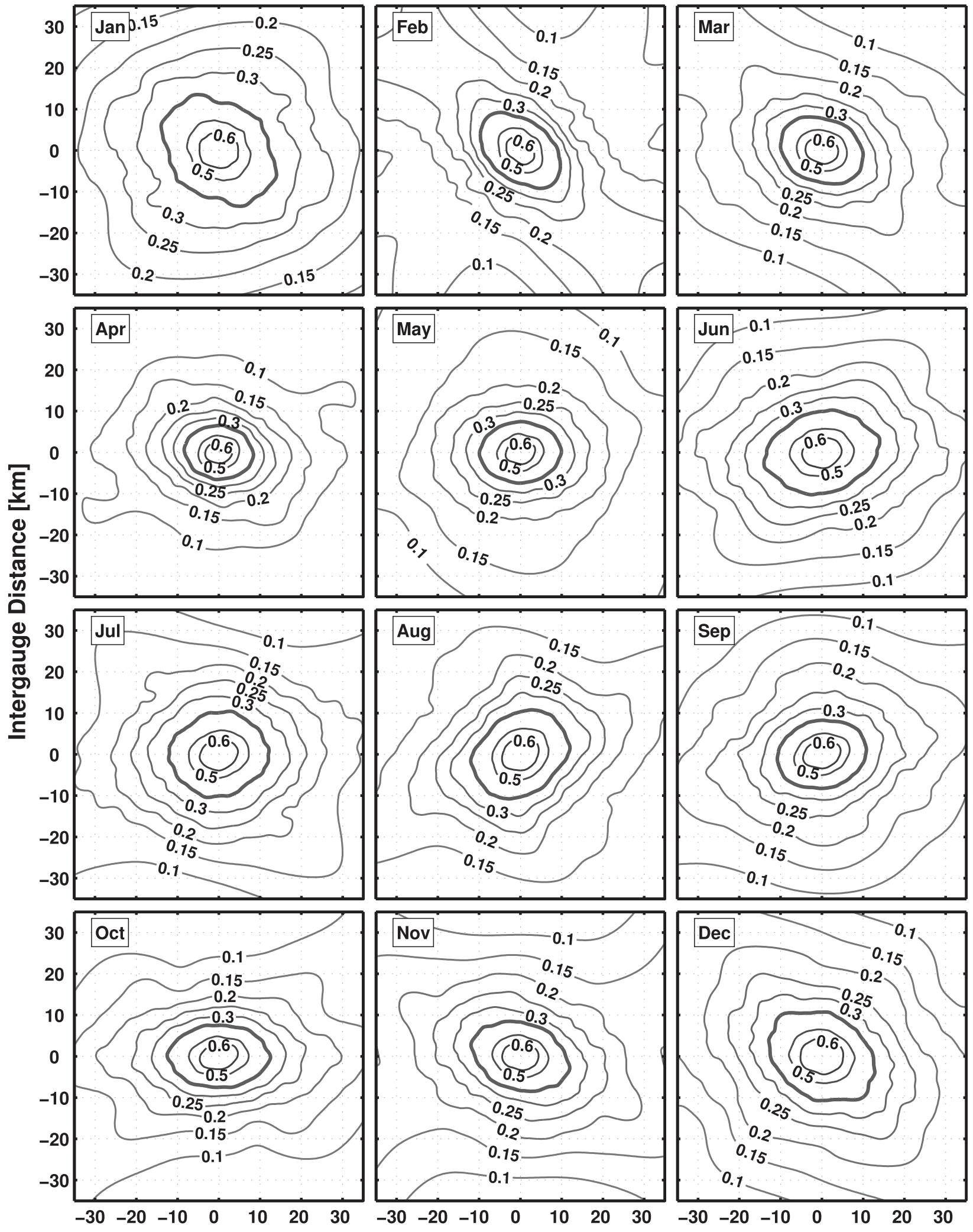

Intergauge Distance [km]

FIG. 14. As in Fig. 13, but for each month and limited to hourly time scale. 


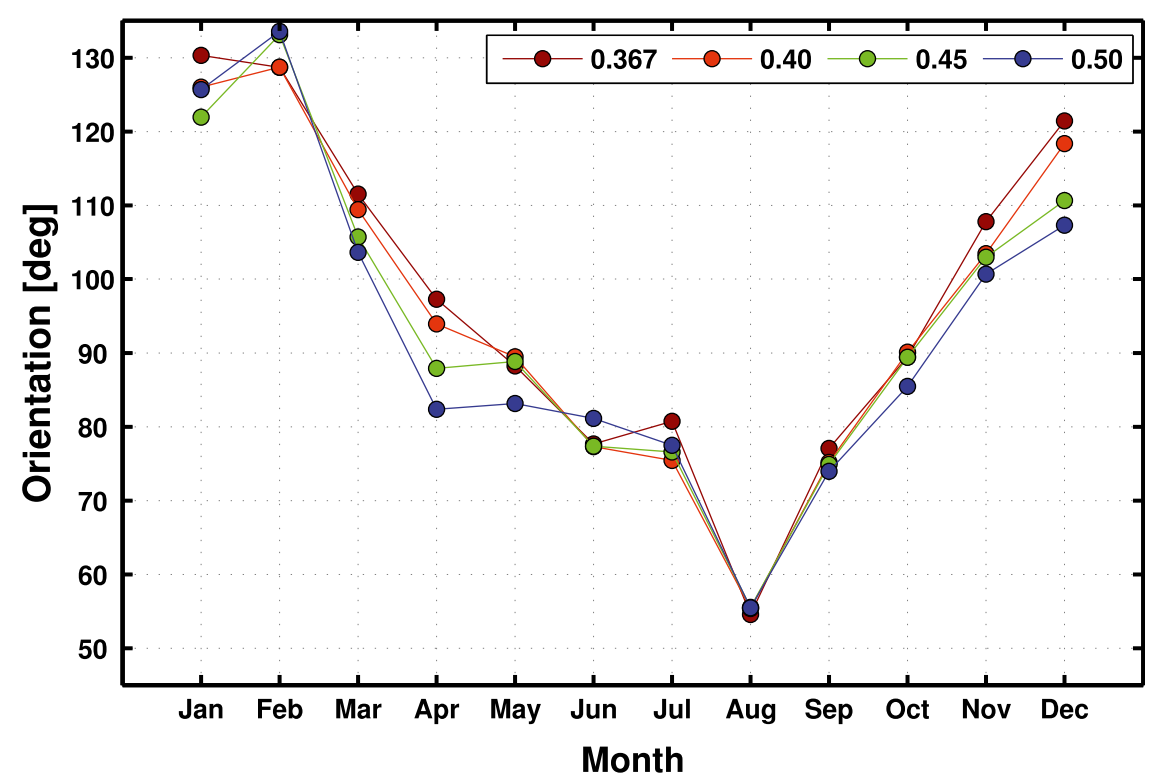

FIG. 15. Monthly variation of the orientation (with respect to north) of the correlation contours of hourly rain rates. The orientation was obtained by fitting an ellipse to each contour.

3) The anisotropic spatial correlation analysis showed that correlation contours were elliptical in shape with an average eccentricity of 0.64 and an orientation of $99^{\circ}$ relative to true north. The orientation and eccentricity of the contours showed considerable dependence on spatial scale. The orientation ranged from $86^{\circ}$ to $96^{\circ}$ for smaller spatial scales $(<10 \mathrm{~km})$ and from $101^{\circ}$ to $106^{\circ}$ for larger scales $(>20 \mathrm{~km})$. In a similar way, average eccentricity was found to be in the range of $0.61-0.65$ for smaller scales and $0.59-0.71$ for larger scales.

4) The eccentricity and orientation of the contours showed significant monthly variability. The average eccentricity of contours was found to be the lowest (0.57) during January and the highest (0.77) during October. The orientation varied from $55^{\circ}$ to $80^{\circ}$ (i.e., WSW-ENE direction) during the southwest monsoon months of June-September and from $100^{\circ}$ to $130^{\circ}$ (i.e., WNW-ESE direction) during the northeast monsoon months of November-March.

This study is a step toward bridging the scale gap in characterizing rainfall structure in Singapore and the surrounding Maritime Continental region. The results would be valuable for evaluating remotely sensed observations from weather radars and satellites and also for quantifying the performance of rainfall downscaling techniques. For example, information about the spatial correlation structure of rainfall is necessary to quantify the areal representativeness error of the gauge network while evaluating remotely sensed observations (e.g., Ciach and Krajewski 1999; Mandapaka et al. 2009). The parametric forms proposed for probability distributions and spatial correlation structure would be useful in generating spatial rainfall ensembles for hydrologic modeling. In addition, the results from this study would serve as a key input to stochastic multisite rainfall generators that take intersite correlations into account (e.g., Brissette et al. 2007; Khalili et al. 2007). To our knowledge, this is the first study in the Maritime Continental region quantifying small-scale $(1-45 \mathrm{~km})$ spatial structure of rainfall and its dependence on time of day, season, and direction for short temporal scales of 1-24h.

Acknowledgments. This study was supported by an Earth Observatory of Singapore (EOS) project (M4080707.B50; M4080891.B50; M4430053.B50) at Nanyang Technological University. The authors appreciate the support from the National Environmental Agency of Singapore for providing rain gauge data. We appreciate the reviewers for their comments and suggestions, which contributed much to improving the clarity of the paper. We also thank Dr. Marco Gabella for his comments on the manuscript.

\section{REFERENCES}

Aldrian, E., and R. D. Susanto, 2003: Identification of three dominant rainfall regions within Indonesia and their relationship to sea surface temperature. Int. J. Climatol., 23, 1435-1452.

Berndtsson, R., 1988: Temporal variability in spatial correlation of daily rainfall. Water Resour. Res., 24, 1511-1517.

Bidin, K., and N. A. Chappell, 2003: First evidence of a structured and dynamic spatial pattern of rainfall within a small humid tropical catchment. Hydrol. Earth Syst. Sci., 7, 245-253.

, and -2006 : Characteristics of rain events at an inland locality in northeastern Borneo, Malaysia. Hydrol. Processes, 20, 3835-3850. 
Brissette, F., M. Khalili, and R. Leconte, 2007: Efficient stochastic generation of multi-site synthetic precipitation data. $J$. Hydrol., 345 (3), 121-133.

Burgueño, A., B. Codina, A. Redaño, and J. Lorente, 1994: Basic statistical characteristics of hourly rainfall amounts in Barcelona (Spain). Theor. Appl. Climatol., 49 (3), 175-181.

Chang, C., P. Harr, and H.-J. Chen, 2005: Synoptic disturbances over the equatorial South China Sea and western Maritime Continent during boreal winter. Mon. Wea. Rev., 133, 489503.

Chia, L. S., and F. S. Foong, 1991: Climate and weather. The Biophysical Environment of Singapore, D. B. H. Tay, L. S. Chia, and A. Rahman, Eds., National University of Singapore Press, 13-49.

Ciach, G. J., and W. F. Krajewski, 1999: On the estimation of radar rainfall error variance. Adv. Water Resour., 22, 585-595.

- and _- 2006: Analysis and modeling of spatial correlation structure in small-scale rainfall in central Oklahoma. $A d v$. Water Resour., 29, 1450-1463.

Desa, M. N., and J. Niemczynowicz, 1996a: Temporal and spatial characteristics of rainfall in Kuala Lumpur, Malaysia. Atmos. Res., 42 (1-4), 263-277.

$\longrightarrow$, and — 1996b: Spatial variability of rainfall in Kuala Lumpur, Malaysia: Long and short term characteristics. Hydrol. Sci. J., 41, 345-362.

Erdin, R., C. Frei, and R. Kunsch, 2012: Data transformation and uncertainty in geostatistical combination of radar and rain gauges. J. Hydrometeor., 13, 1332-1346.

Fong, M., 2012: The Weather and Climate of Singapore. Meteorological Service Singapore, $228 \mathrm{pp}$.

Germann, U., and I. Zawadzki, 2002: Scale-dependence of the predictability of precipitation from continental radar images. Part I: Description of the methodology. Mon. Wea. Rev., 130, 2859-2873.

Ha, K.-J., E.-H. Jeon, and H.-M. Oh, 2007: Spatial and temporal characteristics of precipitation using an extensive network of ground gauge in the Korean peninsula. Atmos. Res., 86, 330339.

Habib, E., W. F. Krajewski, and G. J. Ciach, 2001: Estimation of rainfall interstation correlation. J. Hydrometeor., 2, 621-629.

Hanson, L., and R. Vogel, 2008: The probability distribution of daily rainfall in the United States. Proc. World Environmental and Water Resources Congress, Honolulu, HI, American Society of Civil Engineers, 1-10.

Hosking, J. R. M., 1990: $L$-moments: Analysis and estimation of distributions using linear combinations of order statistics. J. Roy. Stat. Soc., 52B, 105-124.

—, and J. Wallis, 1997: Regional Frequency Analysis-An Approach Based on L-Moments. Cambridge University Press, 224 pp.

Huff, F., and W. Shipp, 1969: Spatial correlations of storm, monthly and seasonal precipitation. J. Appl. Meteor., 8, 542-550.

Ichikawa, H., and T. Yasunari, 2006: Time-space characteristics of diurnal rainfall over Borneo and surrounding oceans as observed by TRMM-PR. J. Climate, 19, 1238-1260.

Kedem, B., and L. Chiu, 1987: On the lognormality of rain rate. Proc. Natl. Acad. Sci. USA, 84, 901-905.

Khalili, M., R. Leconte, and F. Brissette, 2007: Stochastic multisite generation of daily precipitation data using spatial autocorrelation. J. Hydrometeor., 8, 396-412.

Krajewski, W. F., G. J. Ciach, and E. Habib, 2003: An analysis of small-scale rainfall variability in different climatic regimes. Hydrol. Sci. J., 48, 151-162.
Mandapaka, P. V., W. F. Krajewski, G. J. Ciach, G. Villarini, and J. A. Smith, 2009: Estimation of radar-rainfall error spatial correlation. Adv. Water Resour., 32, 1020-1030.

Mori, S., and Coauthors, 2004: Diurnal land-sea rainfall peak migration over Sumatera Island, Indonesian Maritime Continent, observed by TRMM satellite and intensive rawinsonde soundings. Mon. Wea. Rev., 132, 2021-2039.

Moron, V., A. W. Robertson, M. N. Ward, and P. Camberlin, 2007 Spatial coherence of tropical rainfall at the regional scale. J. Climate, 20, 5244-5263.

Pedersen, L., N. E. Jensen, L. E. Christensen, and H. Madsen, 2010: Quantification of the spatial variability of rainfall based on a dense network of rain gauges. Atmos. Res., 95, 441-454.

Qian, J.-H., 2008: Why precipitation is mostly concentrated over islands in the Maritime Continent. J. Atmos. Sci., 65, 1428-1441.

Sharon, D., 1978: Rainfall fields in Israel and Jordan and the effect of cloud seeding on them. J. Appl. Meteor., 17, 40-48.

Stol, P., 1972: The relative efficiency of the density of rain-gage networks. J. Hydrol., 15 (3), 193-208.

Suhaila, J., S. M. Deni, W. Z. W. Zin, and A. A. Jemain, 2010: Spatial patterns and trends of daily rainfall regime in peninsular Malaysia during the southwest and northeast monsoons: 1975-2004. Meteor. Atmos. Phys., 110 (1-2), 1-18.

Sumner, G., and M. Bonell, 1988: Variation in the spatial organisation of daily rainfall during the North Queensland wet seasons, 1979-82. Theor. Appl. Climatol., 39 (2), 59-72.

Tangang, F. T., L. Juneng, E. Salimun, P. N. Vinayachandran, Y. K. Seng, C. J. C. Reason, S. K. Behera, and T. Yasunari, 2008: On the roles of the northeast cold surge, the Borneo vortex, the Madden-Julian oscillation, and the Indian Ocean dipole during the extreme 2006/2007 flood in southern peninsular Malaysia. Geophys. Res. Lett., 35, L14S07, doi:10.1029/2008GL033429.

Teo, C.-K., T.-Y. Koh, J. C.-F. Lo, and B. C. Bhatt, 2011: Principal component analysis of observed and modeled diurnal rainfall in the Maritime Continent. J. Climate, 24, 4662-4675.

Tokay, A., and K. Öztürk, 2012: An experimental study of the small-scale variability of rainfall. J. Hydrometeor., 13, 351365 .

Varikoden, H., B. Preethi, A. A. Samah, and C. A. Babu, 2011: Seasonal variation of rainfall characteristics in different intensity classes over peninsular Malaysia. J. Hydrol., 404 (1-2), 99-108.

Velasco-Forero, C. A., D. Sempere-Torres, E. F. Cassiraga, and J. J. Gómez-Hernández, 2009: A non-parametric automatic blending methodology to estimate rainfall fields from rain gauge and radar data. Adv. Water Resour., 32, 986-1002.

Villarini, G., P. V. Mandapaka, W. F. Krajewski, and R. Moore, 2008a: Rainfall and sampling uncertainties: A rain gauge perspective. J. Geophys. Res., 113, D11102, doi:10.1029/ 2007JD009214.

— , F. Serinaldi, and W. F. Krajewski, 2008b: Modeling radarrainfall estimation uncertainties using parametric and nonparametric approaches. Adv. Water Resour., 31, 1674-1686.

Vogel, R., and N. Fennessey, 1993: $L$ moment diagrams should replace product moment diagrams. Water Resour. Res., 29, 1745-1752.

Watts, I. E. M., 1955: Rainfall of Singapore island. J. Trop. Geogr., 7, 1-71.

Zawadzki, I., 1973: Statistical properties of precipitation patterns. J. Appl. Meteor., 12, 459-472.

Zhou, L. and Y. Wang, 2006: Tropical Rainfall Measuring Mission observation and regional model study of precipitation diurnal cycle in the New Guinean region. J. Geophys. Res., 111, D17104, doi:10.1029/2006JD007243. 